\title{
A INVISIBILIDADE DE SI DO POVO BRASILEIRO NA OBRA DE DARCY RIBEIRO
}

Marcos Antonio de França ${ }^{1}$

\begin{abstract}
Resumo
Nesse artigo pretendemos abordar, do ponto de vista filosófico, alguns temas relacionados ao trabalho de Darcy Ribeiro como antropólogo e idealizador de uma gênese do povo brasileiro e de sua identidade. A obra pontual a que nos ativemos foi justamente $O$ povo brasileiro. Trouxemos também uma reflexão mais profunda de como se instaura a desigualdade social atrelada a questão racial.
\end{abstract}

Palavras-chave: Identidade; povo brasileiro; Darcy Ribeiro.

\section{THE INVISIBILITY OF SELF OF THE BRAZILIAN PEOPLE IN THE WORK OF DARCY RIBEIRO}

\begin{abstract}
In this article we intend to approach, from the philosophical point of view, some themes related to the work of Darcy Ribeiro as an anthropologist and idealizer of a genesis of the Brazilian people and their identity. The punctual work to which we activate was precisely "The Brazilian people". We have also brought a deeper reflection on how social inequality, linked to the racial question, is established.
\end{abstract}

Keywords: Identity; Brazilian people; Darcy Ribeiro. 
Meu sentimento era de que nos faltava uma teoria geral, cuja luz nos tornasse explicáveis em seus próprios termos, fundada em nossa experiência histórica. As teorizações oriundas de outros contextos eram todas eurocêntricas demais e, por isso mesmo, impotentes para nos fazer inteligíveis. ${ }^{2}$

A impossibilidade de uma configuração concreta, de uma visibilidade de si do povo brasileiro é o tópico que quero abordar nesse momento. Por isso, recorri ao pensamento de Darcy Ribeiro para essa cruzada acreditando ser ele um dos maiores exponenciais no tangente a essa questão. Acercando-se do tema, encontramos certos dilemas que chamam a atenção e pedem urgentissimamente prévias advertências com relação ao método. Com efeito, nossa abordagem pretende ser filosófica e o trabalho filosófico tem lá suas especificidades - como tantos outros. Noto que se tem perdido muito dessas especificidades na maneira apressada com que se tacha tudo como sendo filosófico ou pertinente a filosofia propriamente dita.

Não que o campo da filosofia seja limitado, ao contrário, ele é a ampla planície donde derivam muitos outros campos e perspectivas e, no entanto, em contrapartida, não é derivado de nenhum deles. A raiz da questão está em que, justamente por não se colocar à disposição de nenhuma ciência em particular, a Filosofia está sempre à espreita da sublevação dos limites imposta por qualquer tipo de ciência. É fato que essa não é a visão que encontramos corriqueiramente, pois a filosofia parece relegada a campos muito específicos sendo tratada assim mais como uma "matéria" ou "ciência" em meio a tantas outras. Vou então assumir a tese de que isso é uma herança da clássica da divisão relacional entre sujeito e objeto que é o que configura o fazer científico.

Pois bem, toda a ciência, e isso é a sua condição, se distingui pelo seu método ou pela maneira com que expõe e analisa seus objetos particulares, sendo assim a filosofia também estaria reduzida ao método que lhe caberia para executar suas tarefas. Mas que método seria esse, visto que não prescindiria da relação com um objeto específico, e essa relação é sempre uma forma de restrição? Se considerarmos o campo amplo da filosofia diríamos que esse objeto é o pensamento, mas pode o pensamento ser objeto do pensamento? Mas para isso teria que abstrair o pensamento e tomá-lo numa perspectiva bem mais restrita, e também mais hegemônica. A solução arbitraria para esse problema se encontra na fundamentação do antropocentrismo e na gestação de uma antropologia.

Fiz essa pequena digressão na tentativa de mostrar a cadeia evolutiva que faz surgir um pensamento capaz de ser analisado como "objeto" e também para tentar mostrar como a filosofia repentinamente se colocou como ciência. Não que o objeto dela seja restritivo ao homem, o que justificaria a antropologia, mas por mais que ela tivesse 
o pensamento como objeto num espectro mais amplo, assim mesmo ainda teria que ser num sentido abstrato para que pudesse ser objeto de estudo. No entanto, também devemos alertar para o movimento que a leva a tornar-se um fazer anterior ao saber. E qual seria a diferença? A diferença está na ordem em que se colocam as coisas. Em primeiro lugar, o saber, estando ligado mais ao que seria a sabedoria, prescinde de método específico. Dizendo de outro modo, ele se funda na experiência vivida por todo e cada um particular criando assim o que condicionou-se chamar de costume. Não é necessário que se funde um método único para que se cumpra uma ação, pois as próprias circunstâncias mediam as ações. Basta a observância do que é útil para todos e qualquer um. Útil aí não se relaciona ao uso para alcançar um fim particular, mas sim para equilibrar um todo. Em resumo, o saber em si não necessita de regra nenhuma, tão pouco de método. $\mathrm{O}$ homem, assim como os animais, não precisou de regras para saber o que é bom para ele ou o que lhe impõe algum perigo.

Com efeito, a filosofia estaria ligada ao saber efetivo gestor da prática tida assim como ação, justificando assim o seu campo mais amplo em relação as limitações específicas de cada componente da Natureza, passível de ciência. De forma alguma isso configura uma independência de uma coisa em relação a outra. Também, de forma alguma quer-se dizer que a filosofia não é prática de maneira alguma. O que está em jogo é a visão que se tem dos espectros de abrangência de cada campo. Por ser anterior e as vezes até simultânea com algumas práticas ela pode ser criadora de algumas regras, mas não de regras que devam ser perpetuadas por campos estáticos de conhecimento e de forma alguma restrita à uma só perspectiva. A pressa de comparar a filosofia como algo puramente intelectual, tendendo a confundir a ação com o pensamento, é que acaba por limitar o campo de reflexão da filosofia, pois como mostra a exposição anterior, o pensamento como objeto no campo ideológico se reduz a uma só perspectiva, e dessa forma ela se torna assim uma mera ciência ou título de ciências que a relegam ao segundo plano. Dizendo de outra forma, é como se a ciência ou ciências, antecedessem a própria filosofia, tida como saber, e essa fosse estritamente dependente das múltiplas facetas expostas pelos fazeres científicos.

Podemos então, em consequência disso, prever uma ascensão da razão - formula criada para explicar o pensamento - sobre o próprio saber. Uma antecipação dessa razão em detrimento da totalidade e possibilidade do que é um saber. Assim, a partir do momento que essa razão se caracterizar exclusivamente como humana surge o antropocentrismo que se caracteriza como sendo a razão humana sobreposta a todas as outras formas de existência possíveis e, sobretudo, acima de toda a forma de saber. Mas a pergunta que cabe aqui é: que tipo de humano é esse que detêm a razão? Pois ao criar esse tipo específico de humano, ele próprio tem que ser desvelado em sua constituição. Na medida em que o saber, que não está determinado pelo método, é 
substituído pelos rigores do pensamento racional, ele simplesmente cria um nicho exclusivo e faz com isso aparecer o que não é racional, ou seja, aquilo que não segue ou participa do método. Mesmo que se conceda que há graus de razão, o que se consegue com isso é o ordenamento ou classificação de objetos abstratos que, por si só, ainda prestigia uma só perspectiva. E o pior: arrasta para dentro da própria espécie, pretenso sujeito da operação, essa classificação. Dito de outro modo, dentro da própria humanidade da qual se compõe os homens se pode afirmar uma classificação por nível de razão.

Com efeito, os poucos privilegiados pela razão, se veem como superiores aos que dela não participam. E assim se criam inúmeros discursos para mostrar que mesmo dentro dos corpos racionais, pululam massas inteiras de seres que tem grau de razão menos acentuados e que através do método podem eles alcançar o avatar dos seres puramente racionais ou descambarem para o abismo das bestas irascíveis e inferiores. Tudo isso foi engendrado em um determinado local e tempo com a intenção de se tornar regra universal e se expandir para o resto do que se poderia chamar de mundo. E assim, num jogo de claro/escuro, de afirmação pela negação é que se fundamentou o projeto de melhorar os que aparentemente, em relação a uma perspectiva, estavam perdidos ou danificados. Isso tudo fará mais sentido quando notarmos, já entrando no mundo de Darcy, que o branco europeu chegando aqui, teve que tentar convencer os índios, nativos e donos da terra, a adotarem três sentidos diferentes, valores, que para eles não faziam nem um sentido, qual sejam: a utilidade, a necessidade, e o medo.

Esses pontos podem parecer conflitantes, mas é necessário expô-los visto que de forma alguma seria fácil transitar da filosofia a uma "ciência" específica, no caso a antropologia, passar de um campo restrito para um universo totalmente atento para a efetividade real e singular de cada um dos seres que compõe seu fazer - que o digam aqueles que tentam fazer pontes entre ciências diversas usando do que pretendem ser uma filosofia. O reduto da filosofia é o concreto, inapreensível em seu eterno movimento. Usei o termo "fazer", pois vemos onde pode se encontrar o cerne de toda a confusão que queremos expor. Por exemplo: as ciências trabalham com os sedimentos de tempo, por si só já abstraídos do movimento com que a natureza dotou a existência. Dessa forma procuram compor o que chamariam de História e assim tentariam mostrar um quadro evolutivo. De forma alguma se apresenta aqui uma impossibilidade com relação à uma história da filosofia nesses termos ou de qualquer outra História. O que é aflitivo é que em muitos campos científicos essa história tem lá sua coerência, mas não acredito que isso se dê na filosofia justamente pelo caráter atemporal de seu conteúdo, visto que é um computo de saberes muito simples e não de fazeres complexos. A filosofia está sempre se fazendo para além de qualquer mensuração. Procuramos aqui advertir apenas dificuldades a serem transpostas. 
Analisar a obra de Darcy desde o ponto de vista filosófico nos coloca essa dificuldade. Portanto, temos que colocar a possibilidade da própria filosofia em um campo mais universal para que possamos entender o pensamento em seu teor abrangente como experiência de vida e não como método calcado em princípios abstratos para fins mais abstratos ainda, ou seja, desdenhando os dados estatísticos que de nada servem para causar o desenvolvimento daquilo que diz respeito à um povo em seu movimento concreto que, de certa forma, como a filosofia, está sempre se fazendo. Essa talvez seja a grande "carta na manga" do povo brasileiro que por não aceitar as formulas estáticas da civilização, pretende estar sempre em busca da novidade. Logo, é de bom alvitre que nos coloquemos em alerta para que possamos colher não uma análise rasa e superficial do pensamento desse homem vivido que é Darcy Ribeiro, mas, mergulhando um pouco mais afundo, procuraremos entender qual o verdadeiro ânimo em que ele nos se apresenta e se de fato ele busca como finalidade ser "útil". O grito contido em "O povo brasileiro" e o grito pela identidade desdichada e desconstruída através dos tempos em detrimento do construto social alienígena e aceito como hegemônico. Dado que foi a maneira que o europeu, cultor do tipo de pensamento que expusemos acima, qual seja, o abstrato, achou para invadir as Américas. A invisibilidade de si do povo brasileiro e fruto desse processo.

Esse "sentir-se", mas não "ver-se", que compõe a tendência do povo brasileiro, é o resultado de centenas de anos de esquecimento do que lhe é substancial, de sua própria essência. Mas o que é a essência? Nesse sentido é aquilo que não pode ser mudado ou perdido, sem que todo o conjunto constitutivo se aniquile. É a verve mais profunda do ser dos homens. Dessa forma, o branco europeu, teve que atravessar o mar para ensinar ao índio o que era utilidade, necessidade e o medo. No caso do medo, contrastado com outro sentimento, sentimento esse traduzido nas pregações dos jesuítas em seu projeto "salvadorístico" e messiânico, é a esperança. Esses dois elementos, medo e esperança, base de tudo aquilo que constituiu o pensamento político para o europeu, agora haveria de fazer parte do cotidiano daquela gente que aqui se encontrava. Uma gente num estado puro e desprevenida contra toda a novidade que aqueles homens feios traziam. Feios, pois como o próprio Darcy nos relata, carcomidos pelo escorbuto e pelas pestes que se apresentavam pela longa viagem mar a fora; barbudos e cabeludos; sedentos de água fresca, comida e sexo. A existirem dessa forma, ao se apresentarem assim, só podiam ser deuses ou demônios.

Aliás, foram várias as novidades que o branco europeu trouxe de além-mar. Em meio aos badulaques e colares de conta, vieram também os objetos de ferro, facas, facões, anzóis, e tantos outros que pareciam ser presentes dos deuses/demônios. O europeu trazia pronto o que a indiada daqui só iria, talvez um dia, encontrar em seu percurso em direção ao futuro. Digo talvez, pois, nada daquilo tudo era necessário até então e provavelmente nunca seria. Esses artefatos impuseram por 
si sua necessidade de uma forma tão violenta que depois de tê-los visto e experimentado suas utilidades, se tornaram parte vital do cotidiano daquela gente. Assim a passagem da idade da pedra, polida com engenho, para a idade dos metais, aqui, não foi um dado natural e sim um evento forjado por aqueles que dali por diante iam ser os agentes históricos da nossa condição. Os que contariam nossa história desde seu ponto de vista. Consequentemente, de uma maneira arbitrária, eles tiravam a nossa autonomia, a nossa possibilidade de nos tornarmos sujeitos históricos para nos relegar a condição de meros sujeitados sem condições de tomar as rédeas de nosso destino. Esse mito perdura ainda hoje, quando, desdenhando a nossa capacidade criativa, nos embrenhamos pelas buscas de modelos alienígenas para nos guiar.

Mas não é só isso que veio no bojo dos navios. Para que isso tudo fizesse sentido, era necessário que um cenário fosse criado e fomentado entre aqueles povos. Como disse, tiveram que ensinar o medo que é à base de toda a escravidão, depois a esperança, que todo o medo é passageiro e que há uma redenção mais para além disso tudo. Imaginem um missionário apresentando um Deus paradoxal que ao mesmo tempo em que ama seus filhos, os coage pelos castigos de chamas eternas e dor sem fim: um Deus mau. Junto com o novo sentido de utilidade, representado nos apetrechos de ferro, e de necessidade incutiu-se também um novo sentido e trabalho e de produção: o cumulativo. Aquilo que a indiada via como facilitador, verdadeiramente haveria de torna-se sua ruína. Todo um modo de vida seria abalado por essa novidade de todas a mais perversa.

A ideia era de que se essas facilidades trazidas pelo artefato de metal adiantassem o serviço, sobraria mais tempo para caçar, pescar e viver. Mas, o que aconteceu foi o contrário. Com tudo isso primeiro veio um modo de produção distinto daquele que era o cultuado pelo índio, como dissemos o cumulativo, e que mostrava que ao invés de produzir para si eles teriam que produzir para os outros, no caso os brancos. Configura-se assim a escravidão.

A escravidão não foi uma invenção do lusitano, ela sempre esteve presente onde quer que houvesse "civilização". No entanto a grande invenção mesmo foi transformar o tramite de corpos humanos em negócio. Um negócio dos mais lucrativos que já se pôde implantar na história. Primeiro foram os negros na África. Depois de "descoberto" o novo continente, a escravidão se estendeu para os povos nativos. Mas o que vai interessar é justamente o processo de formação dessa gente nova e como se pode fazer um povo esquecer-se de si. Para isso vamos acompanhar Darcy Ribeiro em seus pensamentos.

Entre os elementos presentes na formação do que seria o povo brasileiro temos o índio, nativo da terra, o negro, trazido da África, e o branco, vindo da Europa. Da mistura dessas três matrizes temos: o mameluco, resultado do pareamento do índio com o branco e o mulato, resultante do pareamento do negro com o branco. Esses dois casos, o mameluco e o mulato são os que mais interessam, pois servem de 
fundamento para o ponto do qual pretendemos partir para expansão do que poderemos chamar de uma resistência interna, presente no povo brasileiro ao que não cabe em nossa identidade. Como nos aponta Darcy:

O brasilíndio como o afro-brasileiro existiam numa terra de ninguém, etnicamente falando, e é a partir dessa carência essencial, para livra-se da ninguendade de não-índio, não-europeu, não-negro, que eles se veem forçados a criar a sua própria identidade étnica: a brasileira. ${ }^{3}$

Essa "ninguendade" presente na gestão desse povo é aquilo que podemos chamar de não identidade. Dizendo de outra forma, o índio não era mais índio, pois o pai dele era o branco que o repudiava pelo fato de ter já criado uma imagem negativa a respeito daquele povo. Em contrapartida ele olhava para sua mãe índia e não se reconhecia mais como um índio. Assim esse sem pátria ficava comprimido entre ser algo e nada ser. Sem uma identidade ele vagava pelo continente, usando de seus conhecimentos de índio para atacar os próprios índios em busca do reconhecimento do pai brando que, de forma alguma ele conseguia. Esquecido de que carregava na alma a própria identidade, qual seja, a de não ter que pertencer a nenhuma outra, apenas a sua. É claro que isso era um construto psicológico e sociológico.

O próprio termo "mameluco" tem sua história. Ela remonta o projeto árabe de domínio e sujeição dos povos conquistados com a expansão do Islã. Os mamelucos eram os filhos dos conquistados que eram levados para estudar nas madrastas, onde aprendiam os costumes e a língua dos árabes. Esse condicionamento era de cunho, do ponto de vista dos conquistadores, positivo em todos os sentidos pois, seguia risca o dito de que "Deus não cria a imperfeição, o ignorante é uma imperfeição, logo, ele tinha que ser educado". Assim, ali a criança crescia e se identificavam com tudo que aprendiam. Mais tarde, quando se deparavam com suas verdadeiras origens, já não conseguiam mais vê-las como viáveis, e assim passavam a repudiá-las. Perseguindo e matando aos que se opunham ao regime dos dominadores. Não é de se estranhar que a maior parte dos bandeirantes aqui no Brasil eram mamelucos por essência. Do mesmo modo se segue com os negros vindos da África com algumas sutilezas, pois os capitães-do mato também eram mulatos ou negros.

Os negros africanos não estavam ao mesmo pé que os índios aqui no Brasil. Eram agricultores por exigência, artesões em cerâmicas e conheciam desde muito a metalurgia. Já trabalhavam como escravos nas feitorias portuguesas na África e não demorou muito para serem trazidos para o continente brasileiro para engrossar o contingente de mão de obra nos engenhos de cana de açúcar. Dessa massa enorme de negros, de sua mistura nasceu o mulato. Esse que agora não mais se identificava com a África que ficara longe, do outro lado do mar, tão 
pouco se identificava com o índio que aqui habitava e menos ainda com o branco que o escravizava. Agora tinha que inventar um lugar seu que seria escavado no vão aberto entre um povo e outro ao qual ele não tinha pertencimento. Como nos diz Darcy esse seria o povo brasileiro.

Com o passar do tempo, o contingente de negros que engrossava a população brasileira, se confundia entre o negro mesmo e o mulato seu descendente. Chegando em determinado momento a ser grande parte da população dessas terras. É nesse período que começa a grande luta, a luta que nunca termina. A guerra comprida que tanto Ojúobá, personagem do romance de Jorge Amado ${ }^{4}$ fala. A luta de um povo que tenta afirmar a sua identidade. Não nos referimos ao fato de que ele tenha de procurar essa identidade, pois ela já está viva e latente em suas atitudes, em sua criatividade. Por ser assim, a prova disso é que diariamente ela tem que ser suprimida, desencorajada, esmagada. Como nos aponta Darcy: "Seu drama era a situação paradoxal de quem pode ganhar mil batalhas sem vencer a guerra, mas não pode perder nenhuma". ${ }^{5}$ E mais a frente: "A característica distintiva do racismo brasileiro é que ele não incide sobre a origem racial das pessoas, mas sobre a cor da pele" ${ }^{6}$

Com efeito, devemos nos convencer de que o racismo gerado entre nossos povos tem uma característica muito marcante. Está estampado na cor da pele. Em qualquer outro caso de discriminação poderia se dar um jeito de disfarçar ou esconder, maquiar se podemos assim dizer. Mas aquele que está na face do negro ou do índio não tem outra alternativa senão sofrê-lo e encará-lo. Essa marca foi o que possibilitou que o racismo fosse velado visto que as matizes de cor de pele se confundem nas classificações feitas pelos entendidos no assunto. Afora as várias teses de inferioridade de raças propostas pela antropologia do final do séc. XIX e começo do séc. XX que pautaram as ciências ditas positivas que muito contribuiu para o descaso com as populações de pele escura. No Brasil isso também teve sus repercussões pois, quando colocam as classes consideradas inferiores numa condição de pobreza e miséria e naturalizam esse fato com os aparatos científicos nada mais fazem do que avalizar a grande defasagem em que se encontram a grande massa de negros e pardos que compõe mais de $50 \%$ da população brasileira. Assim vemos na história da formação desse povo como isso foi possível.

Darcy se importava com essa história. Ao nos mostrar que era preciso encarnar a desigualdade como base de identidade, mostra os efeitos desse fato. Quando a desigualdade é tomada como fundamento para a identidade, fecham-se os laços de comunicação entre os nichos específicos. Dizendo de outro modo, quando eu primeiro tenho que acentuar a diferença do outro como base para a fundamentação do 
que eu sou, acabo excluindo o outro dessa mesma identidade que eu assumo. Uma negação. O índio mantém-se como índio e não se identifica com o "branco" que é posto do lado de fora. Esse "branco" não é somente o "branco" identificado pela cor da pele, mas qualquer outro que não seja índio. Isso só para citar um exemplo do que se reproduz por toda a sociedade.

A base mesmo de como entender o fenômeno da fundação do povo brasileiro é sempre o de uma afirmação da diferença e, em seguida, uma classificação, um escalonamento se preferirem, que se submete rigorosamente a uma escala de valores baseadas, no caso específico do Brasil, na cor da pele. Por mais que isso se disfarce na miríade de classificações - preto, mulato, pardo, cafuzo, caboclo, ...- de forma alguma se remete a visão externa. É mais uma maneira de acentuar a diferença entre os negros e os brancos, ou seja, ninguém inventou até hoje uma miríade de classificação para os brancos. Branco é branco. Com efeito, o legado de Darcy permanece e muitas questões ainda deverão ser levantadas para que se entenda perfeitamente como se defrontar com o problema do racismo e das desigualdades sociais que assolam nossa sociedade. Para isso é nossa obrigação continuar observando e trabalhando para melhor entender e quem sabe em algum momento poder explicar o que e como isso pode ser diferente. Afinal o próprio Darcy afirmava que "o povo brasileiro é o único no mundo que pode ensinar ao mundo que se pode ser feliz sem trabalhar".

\section{Referências}

RIBEIRO, Darcy. O povo brasileiro: a formação e o sentido do Brasil. São Paulo: Companhia das Letras, 1995.

AMADO, Jorge. Tenda dos Milagres. In: Amado, Jorge. Obras completas de Jorge Amado. 5. ed. São Paulo: Martins, 1970. 